\title{
Using Low-Cost PM Monitors to Detect Local Changes of Air Quality
}

\author{
Mariusz Rogulski* \\ Warsaw University of Technology, Faculty of Building Services, Hydro and Environmental Engineering, \\ Warsaw, Poland
}

Received: 19 June 2017

Accepted: 18 September 2017

\begin{abstract}
Air pollution has a negative impact on human health. To care for air in Poland and around the world its quality is monitored. Thus, it is possible to develop appropriate plans for improving air quality in certain areas. Unfortunately, the number of traditional, professional, and stationary devices is usually insufficient. This article presents the concept of using low-cost PM measuring devices to increase the spatiotemporal resolution of air quality measurements supplementing the network of reference devices. The example of Nowy Sacz shows the use of such devices for the detection of urban areas with locally increased values of pollutants originating from low-level emissions. For this purpose, it has been used and compares data regarding the concentration of PM10 from low-cost devices with data from the referential station. To detect local "hot-spots" it has also applied wind speed measurements. This article shows that local PM hot-spots can be detected - especially on days with low wind speeds.
\end{abstract}

Keywords: low-cost PM monitors, air quality, sensor networks

\section{Introduction}

Air is a very important part of the environment, which also affects other elements. It has implications for living conditions, the condition of ecosystems, and the processes of climate change. The greatest impact of air pollutants on human and animal health are observed in industrial and urban areas [1]. One of the negative phenomena that increasingly occurs in cities is smog.

Classic smog occurs in the winter months. It is caused by low air temperature, which results in higher heating of apartments, especially by people who use low-quality fuel for this purpose. In addition, among other things, due to adverse meteorological conditions (e.g., lack of wind

*e-mail: Mariusz.Rogulski@pw.edu.pl and precipitation), temperature inversion occurs at this time. Photochemical smog occurs in warm months, when the air temperature is about $25-35^{\circ} \mathrm{C}$ and is windless. Its main causes are reactions that occur between the oxides of nitrogen and hydrocarbons from car exhaust and light [2]. As a consequence, harmful compounds are formed. The composition of smog includes, among other things, dusts. It may include hydrocarbons, elemental carbon, silicon compounds, aluminum, iron, trace metals, sulfates, nitrates, chlorides, and ammonium compounds. Dusts in the air are associated with direct emissions, in particular from transport and from municipal sources, but also due to the reaction between substances contained in the air. The most commonly measured particle size indicators are $\mathrm{PM}_{10}$ - particles with a diameter fraction of less than $10 \mu \mathrm{m}$, and $\mathrm{PM}_{2.5}$ - particles with a diameter fraction less than $2.5 \mu \mathrm{m}[1]$. 
Particulate matter (PM) is harmful to human health. It can cause many respiratory diseases, including even lung cancer. A man inhaling air with high concentrations of dust can absorb up to 50 million dust particles per inhalation. Studies show a relationship of exposure to dust with increased mortality of people with pneumonia and circulatory system problems. An example is the rainforest fire in Indonesia in 1997, which caused a significant increase in the number of acute respiratory infections for humans [3-4].

In order to analyze air quality we most often use stationary, professional measurement stations. Measurements made with their use refer to the area around the station. The problem is that there is no information on the concentration of dusts at locations distant from these stations.

The aim of this article is to show the possibility of using measuring devices based on low-cost optical dust sensors to detect local changes of air quality and support reference stations. Section 2 shows the problem of insufficient resolution of measurements made with reference devices and the possibility of using devices based on optical dust sensors. The next section presents a case-study of low-cost PM measuring devices supporting one reference device in Nowy Sacz. The last section is a summary.

\section{Materials and Methods}

In Poland, a survey of the state of the environment is a task of State Environmental Monitoring (SEM), whose objectives have been described in the Act of 27 April 2001: Environmental Protection Law. The main objective of the SEM is to support activities related to the environment. Research under State Environmental Monitoring is conducted by the Environmental Protection Inspectorate, which consists of the Chief Inspectorate for Environmental Protection (CIEP) and 16 Voivodship Inspectorates for Environmental Protection (VIEP).

The results of measurements of air pollutants concentrations (and usually with meteo parameters) from stations that belong to VIEP are transferred to a databases managed by the CIEP. Verified data is used to create reports from special zones where there is a risk of exceeding the air pollution concentration limits, developing short-term air quality forecasts in special zones, reporting, etc. They are also made available to the public.

Locations of stations belonging to the VIEP were established in places that allow us to obtain data from various types of surroundings and are available on individual websites of VIEP. For example, in Warsaw, information on pollutant concentrations provide only 8 automatic stations (including 5 of VIEP) and 3 manual stations. This small number of measurement stations is unable to provide accurate information about air quality. In Warsaw, one station theoretically covers an area of about $47 \mathrm{~km}^{2}$. In fact, the location of the monitoring stations is not evenly distributed. Some monitoring stations, e.g., on Marszałkowska and Aleje Niepodległości streets, are very close together and collect data from the same area. In many other districts there are no measuring stations, so that air quality in areas further from the monitoring station is determined by modeling based on the results obtained from stationary stations. This problem affects many other places in the country where there is a lack or insufficient number of measuring devices.

An insufficient number of professional measuring stations causes increasing interest in low-cost sensors measuring PM concentrations. The reason for this is also the fact that until recently, the measurement of pollutants concentration was only possible with expensive professional equipment operated by highly qualified workers. Secondly, media campaigns and social actions (in the form of different types of "smog alarms") increase awareness of the problem, its sources, and the way in which problems are measured and interpreted.

PM measuring devices can be divided into those that measure mass concentration or number concentration. Mass concentration can be measured directly by changes in the penetration of electrons through the sample (BAM) [5], changes in frequency of an oscillating sensor element [6-8], or indirectly (as value calculated from number concentration) by diffuse light transmission, wherein the particle diameter is estimated by the amount of light dispersed [8]. Currently, only light-based sensors can be produced cheaply, which means that these devices have recently gained a lot of popularity as they can enhance our ability to measure PM concentrations with high spatial and temporal resolution at acceptable costs [9].

Most of the low-cost optical sensors measuring PM concentrations work on a similar principle of using a ventilator to draw air flowing through the chamber. In the chamber, the light generated by the laser passes through the air. Light dispersed on particulate matter is detected by a photodiode detector and converted to $\mathrm{PM}_{1}, \mathrm{PM}_{2.5}$, and $\mathrm{PM}_{10}$ concentrations.

There are many publications on various aspects of research and applications of low-cost optical dust sensors and devices using them. Several low-cost sensors have been tested in real applications [9-12] and in laboratory conditions [12-13]. These tests are promising for PM sensors. [12] performed laboratory studies of three cheap sensors (Shinyei PPD42NS, Samyoung DSM501A, and Sharp GP2Y1010AU0F) that showed that the measurements from these sensors were linearly correlated to professional instruments. [13] found a linear correlation in the concentration range between the Shinyei sensor and the TSI Corp. device. During four-day studies by [10] the Shinyei sensor response in the contaminated Chinese region was examined and they found correlation with professional testing instruments, including gravimetric methods. The examination of two $\mathrm{PM}_{2.5}$ sensors - DustTrak 8520 TSI and Thermo Scientific personal DataRAM - are described in [14]. The authors 
showed that both sensors were quite consistent with gravimetric measurements.

[15] evaluated the efficiency of the Dylos DC1700 pocket instrument and two Sharp measurement sensors when measuring various aerosols at high concentrations. It was demonstrated that all three sensors had a high regression coefficient compared to the mass values made using pDR-1500. [16] compared Sharp GP2Y1010AU0F and Syhitech DSM501A PM sensors and found that although they were generally consistent with reference methods, they were not accurate enough to be used as reference devices. It was indicated that they could be adequate for high spatial and temporal networks, where large amounts of generated data could be used to provide useful information.

In [17] the authors tested four dust sensors: Speck, Dylos 1100 Pro/Dylos 1700, AirAssure PM $_{2.5}$ IAQ Monitor, and AirSense, and compared them with three reference devices (Grimm 1.109, APS 3321, and FMPS 3091). They also pointed to the suitably high quality of the obtained results. When using calibration factors or functions, their applicability would be even greater. In the case of compact devices, their advantage was also the ability to carry out measurements in different situations. The authors also paid attention to additional elements that were included in complete solutions, such as: the ability to view online measurement results on a dedicated website in the absence of a display device. Another addition was, for example, the built-in display of the air quality index (e.g., in the form of an appropriate color) based on the measurements being carried out.

[18] presented results of Plantower PMS 1003/3003 sensor tests in an aerodynamic tunnel and in an outdoor application during winter days. The project indicated that results generated by PMS 1003/3003 were well correlated with the results from the reference method and professional equipment in real conditions as well as in the tunnel. In some cases the sensor worked even better than the other cheaper sensor, although, as the authors pointed out, there was need for further investigation. The feature that characterized it, like many other low-cost sensors, was over-inflated in periods of increased pollution. These results indicated that the evaluation should have been taken at target conditions, and also that it was necessary to develop appropriate correction coefficients. As a conclusion, these sensors were a promising tool for identifying relative increasing or decreasing of PM levels, complementing a network of professional measurement stations.

Many studies also show some disadvantages of lowcost sensors. They are not as accurate and precise as the reference methods and devices [19]. Some have limited sensitivity and may be affected by humidity as well as many other substances. Often the sensors from the same manufacturer and the same series give different measurements [10-12]. Many of these sensors do not provide information on the conditions under which the calibration was performed (if carried out), quality maintenance procedures, or descriptions when sensors

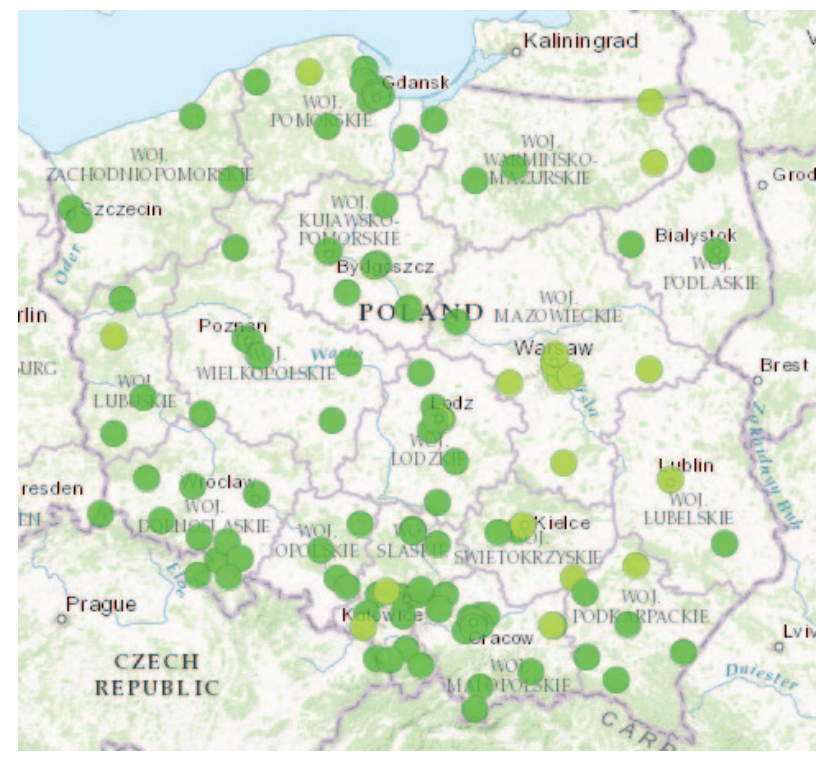

Fig. 1. Locations of automatic stations measuring concentrations of $\mathrm{PM}_{10}$ in Poland (source: CIEP, powietrze.gios.gov.pl/pjp/ current).

may generate inaccurate readings. Despite these potential problems, some organizations collect and publish online PM concentrations, and even publish air quality indexes based on these data [20-21]. It should be taken into account that submitting information from PM detectors of this type can cause either unnecessary social anxiety (in the case of overstated values) or unjustified optimism (in the case of underestimated values) regarding levels of pollution and the associated health risks [19].

The lack of or inadequate number of VIEP measuring devices in many places causes both municipal authorities and local communities to be concerned about the actual air quality in the nearest surroundings. An example of such a town is Nowy Saczz.

Nowy Sacz, located in southern Poland, has more than 80,000 inhabitants and covers $57 \mathrm{~km}^{2}$. The area of the city is quite diverse in many aspects. Some districts are dominated by one-family buildings that are not connected to the urban heating network and therefore have their own fireplaces. In other districts multifamily blocks that are heated from the urban network prevail, and still others are green areas. The city and its immediate surroundings are hilly - the lowest point of the city is $272 \mathrm{~m}$ a.s.l., while the highest is $475 \mathrm{~m}$ a.s.l. In the town there is one air quality monitoring station owned by VIEP (Fig. 2). The nearest VIEP station is located in Tarnów (about $45 \mathrm{~km}$ in a straight line). In Małopolskie Voivodship, the concentration of measurement stations is higher in Kraków and its surroundings (Fig. 1). Official air quality modeling in the Nowy Sacz region is based on data from only one station.

In order to increase the spatio-temporal resolution of air quality measurements in Nowy Sacz, in September 2016 prototype devices constructed by scientists from the Faculty of Building Services, Hydro, and Environmental 


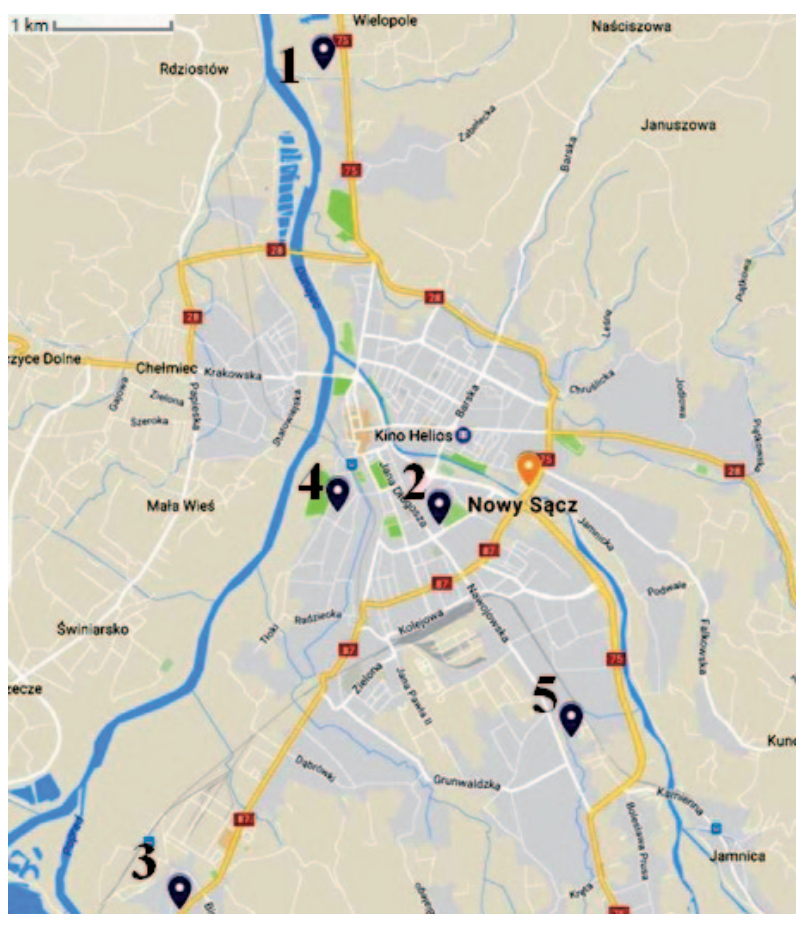

Fig. 2. Locations of prototype measurement stations in Nowy Sacz. For comparison, the VIEP station are indicated by a different color (based on: maps.google.com).

Engineering and the Faculty of Electrical Engineering of Warsaw University of Technology were installed in 5 locations. Their locations have been established in common with the city authorities (Fig. 2). The devices operate 24 hours a day.

The devices are based on microcontrollers to which optical dust sensors and meteo sensors are connected. Prior to installation, dust sensors were pre-tested in the laboratory. Comparisons of device indications with the reference device were made and on this basis calibration functions were developed and the mean percentage errors were calculated (5-10\%, depending on the device).

Every device sends data with measured values to the server every minute. Average hourly PM values are presented online on the city website. The main purpose of mounting the equipment was to increase the resolution of the spatial measurements and to check the value of pollution in the neighborhoods of the city. This allows devices to detect so-called hot-spots, or places where air pollution is much higher than in others.

\section{Results and Discussion}

The month chosen for results analysis was February 2017. This month was characterized by varying weather conditions. The beginning of February was characterized by an average daily temperature slightly above zero, but with cloudy weather and high humidity. At the turn of the first and second decades there were several cooler days (with frosty weather) and with varying cloudy weather.
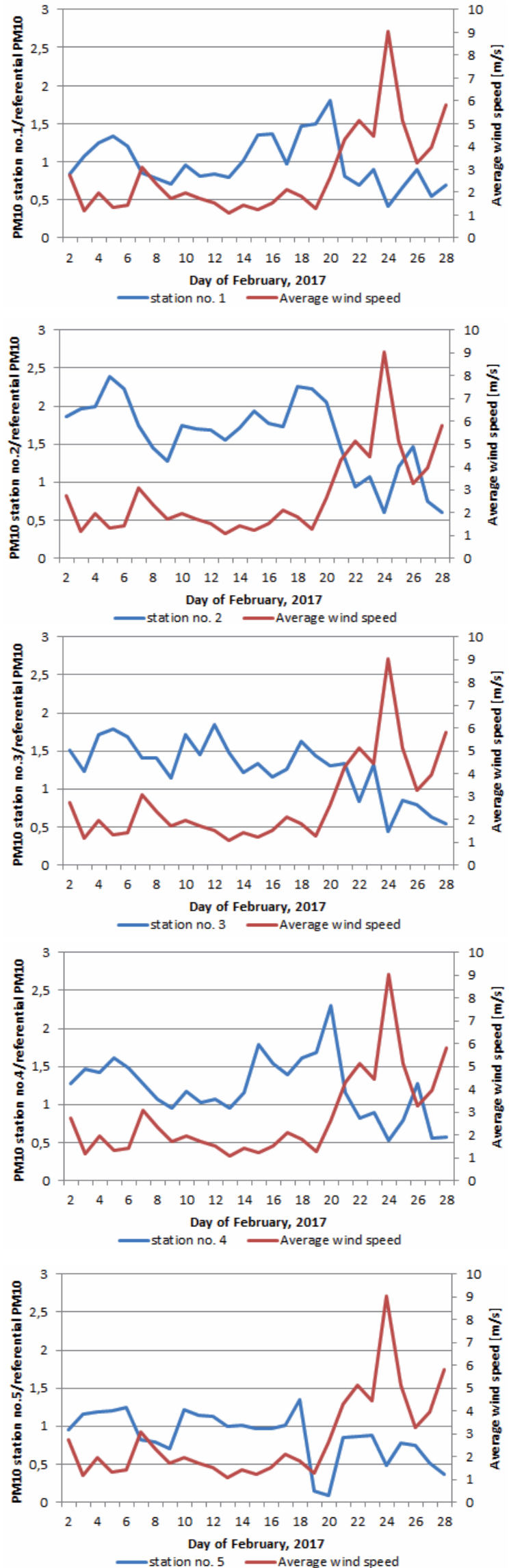

Fig. 3. Average wind speed $(\mathrm{m} / \mathrm{s})$ and ratio of the measured values from the optical sensors to the reference station for each measuring station in February 2017. 
Table 1. Correlation between PM ratio and average wind speed.

\begin{tabular}{|c|c|c|c|c|c|}
\hline Station number & 1 & 2 & 3 & 4 & 5 \\
\hline Correlation coefficient value & -0.589 & -0.802 & -0.753 & -0.623 & -0.457 \\
\hline
\end{tabular}

Starting mid-month there were warmer days, but with high humidity. The end of the month saw further gradual warming (even with the foehn), with more sunshine and less humidity. For meteorological data sources I used data from my own measuring devices. Data about wind power and direction were acquired from the following portals: weatheronline.pl and worldweatheronline.com. In this month, according to data from the reference station, exceeding the permissible level (daily average $\mathrm{PM}_{10}>50 \mu \mathrm{g} / \mathrm{m}^{3}$ ) occurred within 20 days.

The data on wind power are important enough to suggest that areas of the city where significant amounts of pollutants are present will be revealed during the light wind. In the case of a strong wind, generated pollution is immediately transferred so that detection of pollution sources is impossible in this situation. The relationship between average wind speed and measurements of $\mathrm{PM}_{10}$ for each station are shown in Fig. 3. The left vertical axis contains values of the average daily measured values of $\mathrm{PM}_{10}$ concentrations obtained by particular devices divided by the average daily value of $\mathrm{PM}_{10}$ measured by the reference station (PM ratio). The right vertical axis indicates average daily wind speed $(\mathrm{m} / \mathrm{s})$. The horizontal axis is the time (1-28 February 2017). The correlation between PM ratio and average wind speed is shown in Table 1.

In the first half of the month, the average daily wind speed was usually around $2-3 \mathrm{~m} / \mathrm{s}$, which is a weak wind. At the end of the month, the wind speed was significantly increased, with a maximum average value of more than $9 \mathrm{~m} / \mathrm{s}$ on 24 February. Comparing the values of pollution from all stations, it is clear that for all days with strong wind, all optical devices show lower values than the reference station. In addition, the ratio of the measured values from the optical sensors to the reference station values are very close to each other. For 24 February there are about $0.44-0.6$. For such weather conditions it is difficult to identify areas that are specific sources of pollution. This is not too important in this case, because the strong and very strong wind causes pollution not to be concentrated in a small area, but instead lifted and spread to other areas.

However, other conclusions can be noticed if we take into consideration the period of the first and second weeks of February. In the case of station Nos. 1 and 5, the ratio of values measured by optical sensors to reference values oscillates around one. Thus, in the period between 1 and 20 February for station No. 1 the average ratio equals 1.06, while for station No. 5 it is exactly one. We can say that the absolute values of $\mathrm{PM}_{10}$ at these stations are almost identical to the $\mathrm{PM}_{10}$ values measured at the VIEP station. It is also the worst value of correlation coefficient for these two stations. Therefore, there are probably no significant sources of pollutant emissions around these stations that would cause their local over-concentration. This would also indicate the vicinity of the station. Station No. 1 is located on the northern edge of the city, close to the river, surrounded by lots of vegetation, with few sources of dust (chimneys). The distance from the reference point is $4.84 \mathrm{~km}$. Station no. 5 is located in a park-like area, where the surrounding houses are heated by gas furnaces. The distance from the reference point is $2.63 \mathrm{~km}$.

For other stations the situation is definitely different. The highest ratio of measured values to the values from the reference station is for station No. 2, equaling 1.84 . This difference is especially visible for the days with weakest winds, for example on 5 and 6 February it is 2.38 and 2.22, respectively, and 18 and 19 February 2.25 and 2.23. Between 1 and 20 February the slightest difference is on 9 February (1.27), which is confirmed by the highest wind correlation coefficient of -0.8 . The second station with the highest deviation from the reference device (and the highest negative wind correlation coefficient) is station No. 3 . The average ratio value is 1.46 . Between 1 and 20 February the highest daily average ratios were on 12 (1.84) and 5 February (1.79), while the lowest were on 9 February (1.14). For the last station, No. 4, the highest average daily ratios occurred on 20 (2.3) and 15 February (1.78), while the lowest were on 9 and 13 February (about 0.94).

Based on these data it can be stated that among all locations, the area from which the most pollutants are generated ("hot-spot") is the surroundings of station No. 2 , which is located in the city center, where there are relatively dense buildings as well as many sources of dust (chimneys). The distance from the reference station is $1 \mathrm{~km}$. Station No. 3, which is $5.73 \mathrm{~km}$ from the reference station, is installed in a district of single-family houses heated by their own furnaces (not connected to the urban heating network). Station No. 4 is located in an area with rare single-family housing, but quite close to the city center ( $2 \mathrm{~km}$ from the reference station).

During periods of low winds, when it is cold and cloudy and thus conducive to dust accumulation in the air, it is precisely for station No. 2 the greatest difference compared to the reference station. Even better, it is visible if we make an hourly graph for one day. The graph for the day with the highest measured $\mathrm{PM}_{10}$ values (for all stations) is presented in Fig. 4. It is clear on this chart that the greatest discrepancies appear in the evening, when the inhabitants begin to burn intensively in the furnaces. In the evening there were also favorable meteorological conditions for dust concentration: the average wind speed was $1-2 \mathrm{~m} / \mathrm{s}$, the temperature about $0^{\circ} \mathrm{C}$, and total cloudiness. 


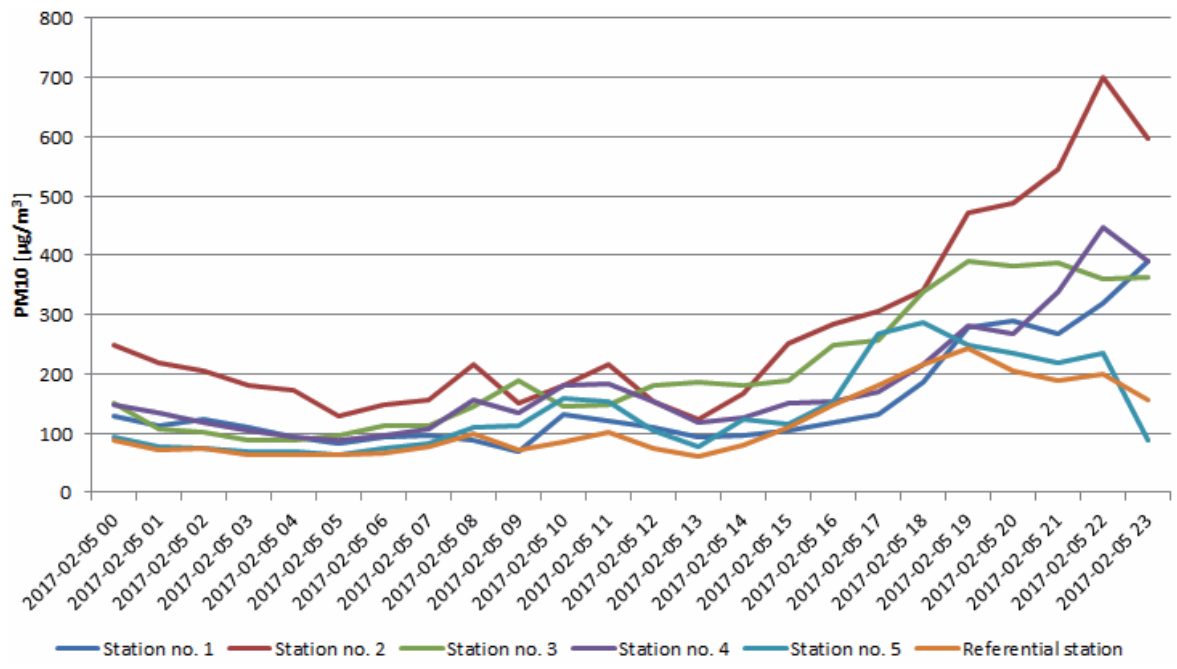

Fig. 4. Hourly averages of $\mathrm{PM}_{10}$ from all stations for each hour on 5 February 2017.

\section{Conclusions}

The above analysis shows that:

- Air parameters observed by one professional measurement station are true in the nearest vicinity of this station; the farther away from it, concentrations of dust may become increasingly different.

- Low-cost devices can be used to increase the number of measurement points; they do not offer such accuracy of measurement as reference devices, but they may indicate some regularity in concentration values over a certain area and their variability over time.

- Low-cost device can detect local pollution hot-spots (in combination with meteo parameters) - especially when the wind is weak (ratio between local pm values and reference station is then the highest); in this way, actions taken to reduce these negative phenomena can be targeted more precisely where they occur.

Complete analysis should take into account air pressure, relative humidity, and wind speed direction. This requires mounting additional devices (e.g., an anemometer) and will be subject to further investigation.

\section{References}

1. CHIEF INSPECTORATE OF ENVIRONMENTAL PROTECTION. The state of the environment in Poland. Report 2014; Agencja Wydawniczo-Reklamowa MAGIC, Warsaw, 2014 [In Polish].

2. SADLOK R. Counteracting low emission in areas of compact residential buildings; Stowarzyszenie na rzecz efektywności energetycznej i rozwoju odnawialnych źródeł energii „HELIOS”, Bochnia, 2014 [In Polish].

3. JURASZKA B., DĄBROWSKI T. Basics of atmosphere protection; Wydawnictwo Uczelniane Politechniki Koszalińskiej, Koszalin, 2011 [In Polish].
4. MING-HO Y. Environmental toxicology: Biological and health effects of pollutants; CRC Press, 2005.

5. KROST K., SAWICKI C., BELL, J. Monitoring airborne particulate mass by beta absorption. Analytical Letters, 10, 333, 1977.

6. PAPROTNY I., DOERING F., SOLOMON P.A., WHITE R.M., GUNDEL L.A. Microfabricated air-microfluidic sensor for personal monitoring of airborne particulate matter: Design, fabrication, and experimental results. Sensors and Actuators A:Physical, 201, 506, 2013.

7. PATASHNICK H., RUPPRECHT E.G. Continuous $\mathrm{PM}_{10}$ measurements using the tapered element oscillating microbalance. Journal of the Air and Waste Management Association, 41, 1079, 1991.

8. SNYDER E.G., WATKINS T.H., SOLOMON P.A., THOMA E.D., WILLIAMS R.W., HAGLER G.S.W., SHELOW D., HINDIN D.A., KILARU P.W., PREUSS V.J. The changing paradigm of air pollution monitoring. Environmental Science and Technology, 47, 11369, 2013.

9. HOLSTIUS D.M., PILLARISETTI A., SMITH K.R., SETO E. Field calibrations of a low-cost aerosol sensor at aregulatory monitoring site in California. Atmospheric Measurement Techniques, 7, 1121, 2014.

10. GAO M., CAO J., SETO E. A distributed network of lowcost continuous reading sensors to measure spatiotemporal variations of $\mathrm{PM}_{2.5}$ in Xi'an, China. Environ. Pollut. 199, 56, 2015.

11. SCAQMD. Draft: Field Evaluation PurpleAir PM Sensor, 2016.

12. WANG Y., LI J., JING H., ZHANG Q., JIANG J., BISWAS P. Laboratory evaluation and calibration of three lowcost particle sensors for particulate matter measurement. Aerosol Sci. Technol., 49, 1063, 2015.

13. AUSTIN E., NOVOSSELOV I., SETO E., YOST M.G. Laboratory evaluation of the Shinyei PPD42NS low-cost particulate matter sensor. PLoS One 10, e0137789, 2015.

14. WALLACE L.A., WHEELER A.J., KEARNEY J., VAN RYSWYK K., YOU H., KULKA R.H., RASMUSSEN P.E., BROOK J.R., XU X. Validation of continuous particle monitors for personal, indoor and outdoor exposures. Journal of Exposure Science and Environmental Epidemiology, 21, 49, 2010. 
15. SOUSAN S., KOEHLER K., THOMAS G., PARK J.H., HILLMAN M., HALTERMAN A., PETERS T.M. Intercomparison of low-cost sensors for measuring the mass concentration of occupational aerosols. Aerosol Science and Technology, 50, 462, 2016.

16. BUDDE M., BUSSE M., BEIGL M. Investigating the use of commodity dust sensors for the embedded measurement of particulate matter. Networked sensing systems. 2012.

17. MANIKONDA A., ZÍKOVÁ N., HOPKE P.K., FERRO A.R. Laboratory assessment of low-cost PM monitors. Journal of Aerosol Science, 102, 29, 2016.

18. KELLY K.E., WHITAKER J., PETTY A., WIDMER C., DYBWAD A., SLEETH D., MARTIN R., BUTTERFIELD
A. Ambient and laboratory evaluation of a low-cost particulate matter sensor. Environmental Pollution, 221, 491, 2017.

19. ISAAC M. Regulatory considerations of lower cost air pollution sensor data performance. Environ. Manage, 7, 32, 2014.

20. BISCHOFF P. New gadget precisely gauges indoor air pollution and finds places with clean air nearby. TechInAsia.

21. PurpleAir Air Quality Map. Available online: http://map. purpleair.org/ (accessed on 25 May 2017). 
